\title{
The motivational implications of adolescents' school-oriented possible identities in a social change context
}

\author{
Nonhlanhla C. Masinga (i) | Kitty B. Dumont
}

School of Interdisciplinary Research and Graduate Studies, University of South Africa

Correspondence

Nonhlanhla C. Masinga, School of Interdisciplinary Research and Graduate Studies, University of South Africa, Florida Campus Johannesburg, PO Box 392, UNISA 0003, South Africa.

Email: masinnc1@unisa.ac.za

\begin{abstract}
In line with the identity-based motivation theory (Oyserman, 2015), which postulates that the motivational implications of possible identities depend on social context, the present research argues that the interplay between accessible possible identities and motivation is also influenced by adolescents' perceptions of social change. According to social identity theory (Tajfel \& Turner, 1986), perceptions of social change were conceptualized as intergroup comparison outcomes, which are assumed to influence the motivational implications of possible identities under the condition that the social change process is perceived as insecure. The results of the present study, which surveyed 631 South African adolescents, supported our assumption. For instance, Black township participants' motivational implications of their possible identities were informed by their identification with Black South Africans. However, the results with regard to white suburb and Black suburb participants were rather ambiguous. The theoretical and practical implications of these findings are discussed in detail.
\end{abstract}

\section{1 | INTRODUCTION}

As individuals are able to reflect on their past and current identities, they are equally able to imagine their future possible identities. Possible identities, which Norman and Aron (2003) defined as cognitively accessible possible selves, might refer to the ideal (i.e., successful), the expected (i.e., parent), and/or feared (i.e., unemployed) selves (Higgins, 1987; Markus \& Nurius, 1986). These possible identities do not only serve as compass in an individual's life but also have motivational and behavioral implications (Markus \& Nurius, 1986). These motivational and behavioral implications of possible identities gave not only rise to theoretical developments (see the identity-based motivation theory of Oyserman, 2015) but also to intervention programs within educational (Oyserman, Terry, \& Bybee, 2002; Salmela-Aro, Mutanen, Koivisto, \& Vuori, 2009) and clinical spheres (Norman, Windell, Lynch \& Manchanda, 2014).

Although everybody holds possible identities, their corresponding domains such as school, career, family, health, or lifestyle differ depending upon individuals' developmental stages or life challenges. Not surprisingly, the most accessible possible identities of adolescents are school-oriented (see Cross \& Markus, 1991) which have been shown to be positively related to both academic attainment (e.g.,
Cunningham, Corprew, \& Becker, 2009) and academic performance (e.g., Anderman \& Anderman, 1999; Hock, Deschler, \& Schumaker, 2006; Leondari, Syngollitou, \& Kiosseoglou, 1998). Although accessibility of school-oriented possible identities is a necessary condition to explain adolescents' academic aspirations it is, however, not always sufficient to explain actual academic achievement as various research with low-income and minority groups demonstrated (see overview by Oyserman, 2013). Consequently, the question is how and under what circumstances do school-oriented possible identities result in relevant behavioral intentions. Answers to this question are provided by the identity-based motivation theory of Oyserman (2015), which addresses the implications of social context for the interplay between accessible possible identities and motivation to achieve or avoid them. For a social context to influence this interplay, it needs to be psychologically salient for the individual. Not surprisingly, most correlative and experimental studies on adolescents' possible identities defined or assumed school or family as the most salient social contexts (Oyserman, Bybee, \& Terry, 2006; Oyserman, Destin, \& Novin, 2015).

However, in unstable societies, that is to say, societies that experience radical social change, other social contexts might be equally important in determining the motivational implications of accessible possible identities (Oyserman, 2015). South Africa is an example of 
such a social change context because as society it aims to redress historical injustices of apartheid by developing conditions for Black ${ }^{11}$ South Africans as majority group to (re)gain social and most importantly, economic power. We, therefore, argue that the changing intergroup relations between white and Black South Africans represent a relevant social change context for adolescents that might influence both the accessible possible identities and their motivational implications.

\section{I ACCESSIBILITY AND CONTEXTUAL FIT OF POSSIBLE IDENTITIES}

Possible identities have motivational and behavioral implications if they are cognitively accessible (e.g., Higgins, 1987; Markus \& Nurius, 1986; Norman \& Aron, 2003). Accessible possible identities are those that can be easily brought into awareness. More specifically, the more accessible a possible identity is the more attention will be paid to it, and the more it will influence an individual's motivation to achieve or to avoid it (Norman \& Aron, 2003, p. 501). According to the identitybased motivation theory of Oyserman (2015), which is rooted in the situated-cognition perspective as outlined by Norman and Aron (2003), the interplay between accessible possible identities and motivation is determined by the social context. More precisely, the theory is based on the assumption that individuals, that interpret situations in ways which are congruent with their currently active identities, prefer identity-congruent actions over identity-incongruent ones, and vice versa. Consequently, the motivational implications of accessible possible identities depend on their fit with the salient social context, that is to say, accessible possible identities that are context congruent have motivational implications. The latter was experimentally demonstrated by manipulating the fit between social context (as success-likely vs. failure-likely school context) and possible identities (as expected vs. feared; see Oyserman et al., 2015). The results showed for instance that motivation was higher in a success-like school context when expected rather than feared possible identities were accessible, while motivation was higher in a failure-like school context when feared rather than expected possible identities were accessible. Thus, possible identities motivate in context, or to say it differently, people act on their accessible possible identities if these identities are congruent with the relevant social context (see also Oyserman, Brickman, \& Rhodes, 2007; Oyserman, Gant, \& Ager, 1995; Oyserman et al., 2015). What happens, however, in a context of social change?

\section{3 | THE ROLE OF SOCIAL CHANGE}

Because of the government-driven affirmative action approach that favors previously disadvantaged groups to redress historical injustices (Employment Equity Act, 2001), South Africa can be seen as a social change context. Given the nature of the South African agenda to

\footnotetext{
${ }^{1}$ The reference to Black South Africans using a capital letter is used within the South African context to summarise previously disadvantaged groups which include African, Indian and Coloured South Africans.
}

achieve social and economic change, it can be assumed that the perceptions of this social change process are informed by interracial comparison outcomes (Tajfel \& Turner, 1986). Intergroup comparison outcomes are often informed by psychological rather than by sociological realities (de la Sablonnière, Bourgeois, \& Najih, 2013; Reynolds, Jones, O'brien, \& Subasic, 2013). For instance, Dumont and Waldzus (2014, 2015) showed that white adolescents tend to perceive the social change process in South Africa as a loss of economic status for their ingroup, whereas Black adolescents perceive it mainly as economic status gain for their group. These psychological realities do not match the sociological realities of current South Africa where the average annual income of Black South African households represents $16 \%$ of the annual average income of white South African households (Statistics South Africa, 2012).

According to social identity theory (Tajfel \& Turner, 1986), the psychological experience of social change, as result of intergroup comparison outcomes, influences individuals' social identities, which in turn can be assumed to influence the implications of possible identities under certain conditions. For instance, if intergroup comparisons result in the perceptions of relative ingroup status loss it can be assumed, according to the identity-based motivation theory (Oyserman, 2015), that feared possible identities are more likely to be context congruent and therefore influence motivation (Hypothesis 1). On the other hand, if intergroup comparisons result in the perceptions of relative ingroup status gain it can be assumed that expected possible identities are more likely to be context congruent and thus influential (Hypothesis 2). Moreover, we would argue that social identities, which are relevant to the social change context, might also be instrumental for motivational implications of possible identities under the condition that social change is perceived as insecure (Dumont \& Waldzus, 2014). The perceptions of insecure social change might result from either resisting the social change process or from experiencing the social change process as not completed yet. In both cases, it is assumed that social identities relevant to the social change context will be salient and instrumental for the motivational implications of possible identities (Hypothesis 3).

\section{4 | THE CURRENT STUDY}

We tested the proposed hypotheses with three groups of adolescents from urban South Africa who differ with regard to their historical and current economic status. The latter was approximated by the school they are attending. The first sample of adolescents belongs to the historically and currently disadvantaged group, which typically lives and attends public schools located in townships (i.e., Black township students). The second sample of adolescents belongs to the historically disadvantaged group but their families currently represent the new middle class of South Africa. These adolescents often reside and attend semi-private schools in suburbs (i.e., Black suburb students). The third sample of adolescents represents the historically and currently advantaged group that resides and attends semi-private schools in suburbs (i.e., white suburb students). According to the national examination results, township and suburb schools have comparable educational 
outcomes in that at least $70 \%$ of their learners complete the 12 -year school program (Department of Basic Education, 2016a). However, suburb schools differ from township schools in that the former produce significantly more learners that meet the basic requirements to attend university (ranging from 64\% to 81\%) when compared to township schools which on average produce $36 \%-41 \%$ of learners that meet those requirements (Department of Basic Education, 2016b).

\section{5 | METHOD}

\section{1 | Participants}

Participants were 631 Grade 10 pupils with an average age of 16.77 years ranging from 15 to 21 . The majority of participants were females (341 compared to 274 males; 16 missings). Participants were distributed to the three groups as follows: white suburb $(n=137)$, Black suburb $(n=147)$, and Black township sample $(n=330)$. Gender was equally distributed in the three samples, $\chi^{2}(1)=0.429, p=.513$.

\section{2 | Procedure}

Paper pencil questionnaires were handed out during the Life Orientation subject. Pupils were informed that the study was interested in their perceptions of their personal futures. Ethical clearance and permission to conduct the study were granted by the University of South Africa, the Gauteng Department of Education and the headmasters of the respective schools.

\section{$5.3 \mid$ Measurements}

Expected and feared possible identities were assessed using the instructions as outlined in the Possible Selves Questionnaire (Oyserman, Bybee, Terry, \& Hart-Johnson, 2004). The expected and feared possible identities were rated by two independent raters in accordance with the Oyserman et al. (2004) classification. This classification distinguishes expected and feared possible identities that are related to academic achievement (i.e., school-oriented), interpersonal relationships, personality traits, physical/health issues, material/lifestyle, and nonnormativity. The interrater reliabilities ranged from a Cohen's Kappa of 0.72 to 0.83 . All remaining ambiguous classifications were discussed by the raters until agreement was reached.

Motivation was assessed by asking participants whether they are currently doing anything to achieve or to avoid the possible identities they named by answering yes or no and by providing examples of their strategies. Each participant could obtain a motivation score ranging between 0 and 8 .

Beliefs about social change between Black and white South Africans were assessed by using the intergroup perception ladder (Dumont \& van Lill, 2009). Participants were asked to imagine that this ladder represents economic status in South Africa. The task of the participants was to indicate their beliefs about which step their ingroup and the respective comparison group stood on in the past (i.e., 25 years ago), today, and in the future (i.e., 15 years' time).
Social change related social identities were assessed as identification with racial groups by first providing participants with the following list of groups: Indians, Whites, Coloreds, Blacks, and Other. After indicating to which group they belong to, they were provided with three items assessing ingroup identification (Leach et al., 2008): "I feel strong bonds with my group," "I am strongly committed to my group," and "Belonging to this group is an important part of me." The internal consistency met the requirement of being larger than 0.70 in all three samples: white suburb sample $(\alpha=0.84)$, Black suburb sample $(\alpha=0.73$ ) and Black township sample $(\alpha=0.75)$.

\section{6 | RESULTS}

\section{1 | Preliminary analysis}

\subsubsection{Accessible possible identities}

Accessibility of possible identities was conceptualized as the ease of bringing such identities into awareness. Consequently, it was assumed that an "easy to imagine possible identity" might come first to mind when participants were asked to report their expected possible identities. Overall, $77.5 \%$ of participants $(n=631)$ first named a schooloriented possible identity. Relationship-related, personality-related, health-related, lifestyle-related, and non-normative related expected possible identities were first mentioned by less than $6 \%$, respectively.

In a first step we tested whether the first named expected schooloriented identities depend on group membership, $\chi^{2}(2)=7.889$, $p<.05$. The adjusted residuals $(> \pm 1.96)$ suggested that Black suburb participants differed significantly from white suburb and Black township participants. The odds ratios indicate that Black suburb participants were 2.14 and 2.08 times more likely to have expected schooloriented possible identities accessible when compared with white suburb and Black township participants, respectively.

Participants were further asked to report on their accessible feared possible identities. A total of $30.4 \%$ of participants $(n=192)$ first named a feared school-oriented identity. Two other accessible feared identities stood out: first, lifestyle-related identities (e.g., being poor) were named by $15 \%(n=94)$ and second, non-normative related identities (e.g., becoming a criminal) were named by $23.6 \%(n=149)$ of participants.

First named feared school-oriented identities was independent from group membership, $\chi^{2}(2)=5.807, p>.05$. However, feared lifestyle-related identities, $\chi^{2}(2)=32.861, p<.001$, and non-normative related identities, $\chi^{2}(2)=19.589, p<.001$, depended on group membership. The odds ratios suggest that white suburb participants were 1.5 and 2.33 times more likely to have feared lifestyle-related identities accessible when compared to Black suburb and Black township participants, respectively; whilst Black township participants were 0.5 and 2.77 more likely to report feared non-normative related identities when compared with Black and white suburb participants, respectively.

\subsubsection{Perception of social change context and identification with social change related social identities}

Figures 1-3 depict the perceptions that the three groups hold with regard to the South African social change process. Notably, Black 


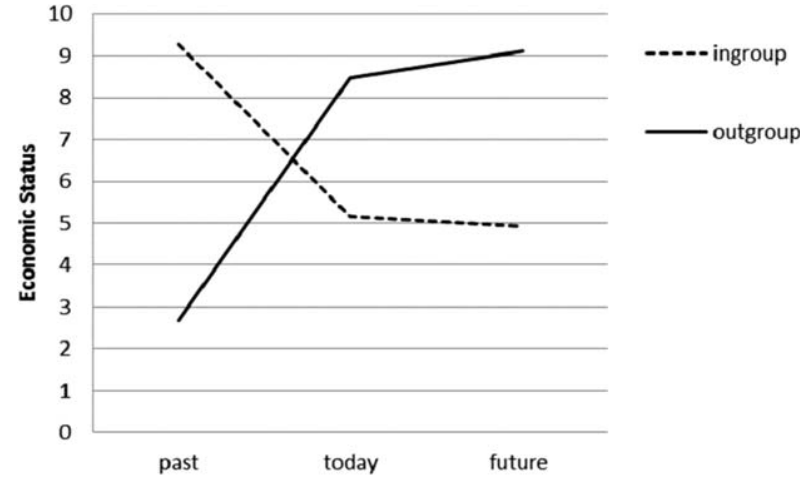

FIGURE 1 Social change perceived by white suburb participants

suburb, Black township and white suburb participants share the overall belief that Black South Africans, as a former disadvantaged group, are the beneficiaries; while white South Africans, as a former advantaged group, are nonbeneficiaries. However, the three groups differ in their beliefs regarding the progress of social change. Black and white suburb participants perceive the current progress of social change as secure in that Black South Africans already gained while white South Africans already lost economic status; a trajectory that is assumed to be stable in the future. Black township participants, on the other hand, perceive the current progress of social change as insecure as they experience the social change as not completed yet (see discrepancy between today's and future intergroup status relations).

Similarly, the three groups differ not only in their beliefs about the social change process but also in their identification with social change related social identities such as racial groups, $F(2,588)=12.875$, $p<.001$. The post hoc statistics, using Bonferroni, revealed that Black township participants identified significantly stronger with their racial group ( $M=5.81, S D=1.17$ ) compared to Black suburb participants $(M=5.23, \quad S D=1.30, \quad p<.001)$ and white suburb participants $(M=5.40, S D=1.26, p<.01)$. Black and white suburb participants did not differ in their racial identification $(p>.05)$.

\section{2 | Hypotheses testing}

We proposed that social change as relative ingroup status loss will increase the probability that feared possible identities are context

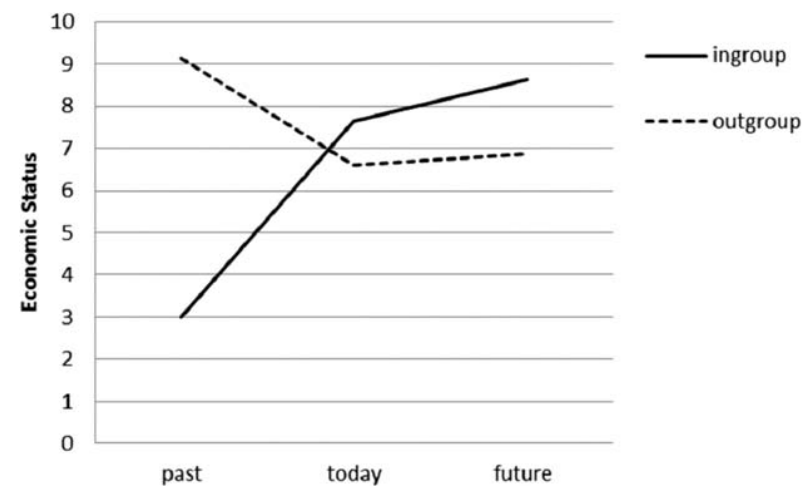

FIGURE 2 Social change perceived by Black suburb participants

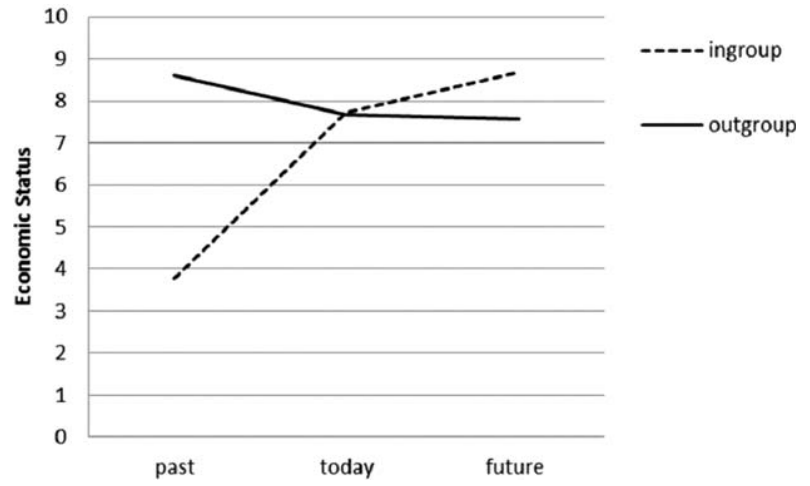

FIGURE 3 Social change perceived by Black township participants

congruent and thus influence motivation (Hypothesis 1); whereas social change as relative ingroup status gain increases the likelihood that expected possible identities are context congruent and thus influential (Hypothesis 2). Moreover, we argued that social identities relevant to the social change context are instrumental for motivational implications of possible identities under the condition that social change is perceived as insecure (Hypothesis 3).

Given the findings of the preliminary analyses, we would assume first that Hypothesis 1, which states that feared possible identities are most likely to influence motivation under the condition that social change is perceived as relative ingroup status loss, is mainly applicable to white suburb participants because they share the belief that their ingroup is losing status relative to Black South Africans. Second, we would assume that Hypothesis 2, which states that expected possible identities will mainly influence students' motivation under the condition of relative ingroup status gain, is mainly applicable to Black suburb and township participants because they perceive their ingroup as beneficiary of the social change in South Africa. Hypothesis 3, which states that social identities relevant to the social change context are instrumental for motivational implications of possible identities, can be assumed to be most applicable to Black township participants because they are the group who perceive the social change process as insecure.

We tested the hypotheses separately for the three groups using multiple regression analysis. Hypotheses 1 and 2 were tested by including the count of coded expected and feared possible identities irrespective of their domains as independent variables; and the participants' motivation scores as the dependent variable. The model for white suburb participants was statistically significant, $F(2,99)=19.35, p<.001$, and explained $26.7 \%$ of the variance of motivation. Motivation was, however, not only significantly predicted by feared possible identities (Beta $=0.224, t=2.29, p=.024$ ) but also by expected identities (Beta $=0.383, t=3.92, p<.001$ ). The regression model was also statistically significant for Black suburb participants, $F(2,94)=16.83$, $p<.001$, and explained $24.8 \%$ of the variance of motivation. Motivation in this model was only predicted by feared identities (Beta $=0.492$, $t=4.491, p<.001)$ and not as assumed by expected identities (Beta $=0.035, t=0.318, p=.751$ ). The model for Black township participants was statistically significant, $F(2,218)=51.47, p<.001$, and explained $31.4 \%$ of the variance of motivation. Motivation in this group 
was predicted by feared (Beta $=0.355, t=4.778, p<.001$ ) and by expected identities (Beta $=0.265, t=3.569, p<.001$ ).

In order to test Hypothesis 3, we extended the models by including identification with racial groups as an additional independent variable. As assumed, the inclusion of identification with the racial group only improved the model for Black township participants, $\Delta R^{2}=0.018$, $F(1,217)=5.868, p=.016$; but not the models for white suburb participants, $\Delta R^{2}=0.005, F(1,98)=0.685, p=.41$, and Black suburb participants, $\Delta R^{2}=0.006, F(1,93)=0.726, p=.396$. Motivation in the extended model of Black township participants was predicted by feared possible identities (Beta $=0.333, t=4.497, p<.001$ ) followed by expected possible identities (Beta $=0.272, t=3.699, p<.001$ ) and identification with Black South Africans (Beta $=0.135, t=2.422$, $p=.016)$.

\section{7 | DISCUSSION}

The present study aimed to contribute to our understanding of adolescents' possible identities within a social change context. In line with identity-based motivation theory (Oyserman, 2015) and social identity theory (Tajfel \& Turner, 1986), we assumed that the psychological experience of social change influences individuals' social identities which in turn influence the motivational implications of possible identities.

The results of the present study confirmed previous findings in that expected school-oriented identities are most accessible in adolescents (Cross \& Markus, 1991; Hooker, Fiese, Jenkins, Morfei, \& Schwagler, 1996). These results suggest that the accessibility of expected school-oriented identities is not necessarily influenced by the social change context. In line with previous studies, school-oriented identities were also accessible as feared possible identities (Oyserman et al., 2004). Moreover, the present study found that lifestyle-related and non-normative related feared identities are accessible as well. Interestingly, the three groups differed with regard to these accessible identities. While Black suburb participants differed from the other two groups in that they were more likely to have expected school-oriented possible identities accessible; white suburb participants differed relative to the other groups in that they were more likely to have feared lifestyle-related identities (i.e., being poor) accessible. Black township participants, on the other hand, differed in that they were more likely to have feared non-normative (i.e., becoming a criminal) identities accessible. Some of the feared identities seem to be related to the adolescents' perceptions of the social change process in South Africa. For instance, the fear of white suburb participants to be poor in the future (i.e., feared lifestyle-related possible identities) corresponds with their perceptions that their ingroup already lost economic status as a result of social change.

Although white and Black suburb participants as well as Black township participants shared the belief that Black South Africans are gaining relative status and white South Africans are losing relative status; they differed in whether they perceive the social change as completed (i.e., secure) or as not completed yet (i.e., insecure). Based on the identity-based motivation theory (Oyserman, 2015) and on the participants' perceptions of social change, we hypothesized that white suburb participants' motivations should be particularly predicted by feared possible identities; whereas Black suburb and township participants' motivations were assumed to be predicted by expected possible identities. For Black township participants it was also assumed that racial identification should influence their motivations. The results of the present study supported our assumptions with regard to Black township participants in that members of this group feel motivated to act not only on their possible identities but also on their identification with their racial group (i.e., identification with Black South Africans). This result supports our basic assumption that the interplay between accessible possible identities and motivation is influenced not only by social context per se but also by its change. However, the results of white and Black suburb participants were rather ambiguous. Although, we found that white suburb participants' motivation was explained by their feared possible identities; their expected possible identities were also influential. Moreover, we found that although Black suburb participants reported significantly more expected school-oriented possible identities their motivations were only explained by their feared possible identities.

The results suggest that the salience of the social change context seems to differ for the three groups under investigation. While the social change context as interracial relations appears to be salient for Black township participants; it seems less salient for white and Black suburb participants. These differences are, however, in line with social identity theory (Tajfel \& Turner, 1986), in that the psychological experience of social change is a result of intergroup comparison outcomes. Given that white and Black suburb participants perceive the South African social change as completed, it might not be surprising that the intergroup comparisons on the societal level are less important for them. The latter does not imply that other intergroup comparisons, for instance on a school level, would not be relevant. The results found for Black suburb participants actually point in this direction. Although they consider themselves as belonging to the group that benefits from the societal changes in South Africa; their motivation as response to their possible identities was essentially informed by fear. This suggests that Black pupils, who attend suburb schools, which in the past were exclusively attended by white South Africans, might experience a social reality within such a school context that is contrary to the grand narratives about the societal changes in South Africa. To be more specific, desegregation of education in South Africa meant mainly that Black adolescents as members of a former disadvantaged group entered educational institutions of the former advantaged group (but not necessarily vice versa). More importantly, the desegregation process followed and still follows a rather assimilationist approach where the values, traditions, and customs of white South Africans frame the social and cultural context of these schools (Soudien, 2004). Thus, it might be that Black pupils attending these schools consider themselves as nonnormative in this context. The latter might explain why their motivation is mainly informed by their feared possible identities (see also Oyserman \& Markus, 1990). 
As any research, the present study has its limitations. One major limitation is that we assessed the impact of social change using a crosssectional research design. Social change is an ongoing and often longlasting process. Consequently, to study its influence on any psychological dynamics appropriately requires a longitudinal approach. A second limitation is the fact that the present study assessed social change and relevant social identities on a societal level. As the results of the present study suggest, changes on for instance school levels (or the lack of it) might even be more relevant for adolescents' possible identities and their implications. Lastly, the present study assessed motivation as available strategies to either achieve or avoid possible identities and more importantly, it did not include measures related to academic achievement. Follow-up studies should overcome these outlined limitations.

Irrespective of the outlined limitations, the present study contributes to research on adolescents' possible identities. First, although previous research stressed the role of social contexts such as school and family in explaining the interplay between possible identities and motivation (Oyserman et al., 2006, 2015); the current study extended this perspective by considering the role of other social contexts which might be particularly influential under the condition of social change. More precisely, the results of the present study suggest that those social contexts are important to adolescents if they perceive social change as still ongoing. For instance, Black township participants that perceived social change in South Africa as not completed yet, attributed more importance to their racial group membership which in turn influenced the motivational implications of their possible identities. Although speculatively, one could argue that the role of social identities beyond school and family might be equally relevant in societies that are highly culturally diverse and/or that are characterized by illegitimate intergroup status differences (Tajfel \& Turner, 1986).

Second, the results of the present study suggest that institutional changes such as desegregation of schools as seen in South Africa are not necessarily inclusive for all adolescents. The latter was obvious for Black suburb participants whose expected possible identities (which were predominantly school-oriented) did not fit their actual school context and consequently, did not contribute to their motivation to achieve them. Their motivations were exclusively informed by their feared possible identities; which means that their ideas about their personal futures are mainly related to avoidance rather than advancement.

Third, the results of the present study underline the importance of social context as psychological reality (de la Sablonnière et al., 2013; Reynolds et al., 2013) by implying that social context influences not only identity content but also its function (Hogg \& Smith, 2007). In the present study, the expected possible identities of participants were mainly influenced by the school context; whereas feared possible identities were influenced by local (e.g., white suburb participants fearing to become poor) or domestic contexts (e.g., Black township participants fearing non-normative identities). Moreover, the results of the present study showed that racial identification is instrumental for the motivational implications of possible identities for those participants that perceive social change as a discrepancy between present and future intergroup status relations (e.g., Black township participants).
Moreover, the findings of the present study have practical implications for both intervention programs and educational policies. As the present results suggest, a changing social context influences not only the accessibility of possible identities but also their motivational implications. Thus, intervention programs that aim at enhancing the positive implications of possible identities need to take cognizance of adolescents' psychological realities with regard to their social context. These psychological realities which are informed by the past and the present might be at times conflicting (for instance, belonging to a group that is minority within a particular school context yet majority within the larger society) and/or threatening (for instance, belonging to a group that is considered by ingroup and outgroup members to lose economic status). In a similar line, the results of the present study also imply that educational desegregation does not necessarily lead to inclusiveness. Consequently, educational policies that aim for inclusiveness at schools need in their implementation to focus not only on the numerical but also on the hierarchical representation of groups (Unzueta \& Binning, 2012); because inclusiveness at any institution requires that norms and values are influenced and shaped by all groups involved in the institution.

The present study is the first study that addresses South African adolescents' possible identities. South Africa is a country with a population largely consisting of young people (i.e., those who are below the age of 35 years constituting about $66 \%$ of the total population). Being such a "young" society, South Africa could benefit from the possible identities of its adolescents in its aim to redress historical injustices and to develop into the imagined "rainbow nation." The latter, however, might require that the social change context is experienced by adolescents as congruent, reassuring, and secure.

\section{ACKNOWLEDGMENTS}

We would like to express our gratitude to Ms. Linda Knoetze and Mr. Sibusiso Maseko from the University of South Africa for their support in collecting and coding the data of the present research.

\section{ORCID}

Nonhlanhla C. Masinga iD http://orcid.org/0000-0001-9353-1385

\section{REFERENCES}

Anderman, E. M., \& Anderman, L. H. (1999). The relation of present and possible academic selves during early adolescence to grade point. Elementary School Journal, 100, 3-17.

Cross, S. E., \& Markus, H. (1991). Possible selves across the life-span. Human Development, 34, 230-255.

Cunningham, M., Corprew, C. S. III., \& Becker, J. E. (2009). Associations of future expectations, negative friends, and academic achievement in high-achieving African American adolescents. Urban Education, 44, 280-296.

de la Sablonnière, R., Bourgeois, L. F., \& Najih, M. (2013). Dramatic social change: A social psychological perspective. Journal of Social and Political Psychology, 1, 253-272.

Department of Basic Education. (2016a). Report on the national senior certificate examinations. Pretoria, South Africa: Department of Basic Education. 
Department of Basic Education. (2016b). School performance report. Pretoria, South Africa: Department of Basic Education.

Dumont, K., \& van Lill, B. (2009). Dominant and non-dominant groups' responses to social change: The economic transformation process in South Africa. South African Journal of Psychology, 39, 432-447.

Dumont, K., \& Waldzus, S. (2014). Group-based guilt and reparation in the context of social change. Journal of Applied Social Psychology, 44, 331-341.

Dumont, K. B., \& Waldzus, S. (2015). Ideal selves as identity management strategies. International Journal of Intercultural Relations, 44, 1-12.

Employment Equity Act. (2001). Employment equity act 55 of 1998. Retrieved from http://www.labour.gov.za/DOL/downloads/legislation/acts/employment-equity/eegazette2015.pdf.

Higgins, E. T. (1987). Self-discrepancy: A theory relating self and affect. Psychological Review, 94, 319-340.

Hock, M. F., Deschler, D. D., \& Schumaker, J. B. (2006). Enhancing student motivation through the pursuit of possible selves. In C. Dunkel \& J. Kerpelman (Eds.), Possible selves: Theory, research, and applications (pp. 205-221). New York, NY: Nova Science.

Hogg, M. A., \& Smith, J. R. (2007). Attitudes in social context: A social identity perspective. European Review of Social Psychology, 18, 89-131.

Hooker, K., Fiese, B. H., Jenkins, L., Morfei, M. Z., \& Schwagler, J. (1996). Possible selves among parents of infants and pre-schoolers. Developmental Psychology, 32, 542-550.

Leach, C. W., Van Zomeren, M., Zebel, S., Vliek, M. L., Pennekamp, S. F., Doosje, B., ... Spears, R. (2008). Group-level self-definition and self-investment: A hierarchical (multicomponent) model of in-group identification. Journal of Personality and Social Psychology, 95, 144-165.

Leondari, A., Syngollitou, E., \& Kiosseoglou, G. (1998). Academic achievement, motivation and future selves. Educational Studies, 24, 153-163.

Markus, H., \& Nurius, P. (1986). Possible selves. American Psychologist, 41, 954-969.

Norman, C. C., \& Aron, A. (2003). Aspects of possible self that predict motivation to achieve or avoid it. Journal of Experimental Social Psychology, 39, 500-507.

Norman, R. M. G., Windell, D., Lynch, J., \& Manchanda, R. (2014). The significance of possible selves in patients of an early intervention programme for psychotic disorders. Early Intervention in Psychiatry, 8, 170-175.

Oyserman, D. (2013). Not just any path: Implications of identity-based motivation for disparities in school outcomes. Economics of Education Review, 33, 179-190.

Oyserman, D. (2015). Pathways to success through identity-based motivation. Oxford, UK: Oxford University Press.
Oyserman, D., Brickman, D., \& Rhodes, M. (2007). School success, possible selves and parent school involvement. Family Relations, 56, 479-489.

Oyserman, D., Bybee, D., \& Terry, K. (2006). Possible selves and academic outcome: How and when possible selves impel action. Journal of Personality and Social Psychology, 91, 188-204.

Oyserman, D., Bybee, D., Terry, K., \& Hart-Johnson, T. (2004). Possible selves as roadmaps. Journal of Research in Personality, 38, 130-149.

Oyserman, D., Destin, M., \& Novin, S. (2015). The context-sensitive future self: Possible selves motivate in context, not otherwise. Self and Identity, 14, 173-188.

Oyserman, D., Gant, L., \& Ager, J. (1995). A socially contextualized model of racial identity: Possible selves and school persistence. Journal of Personality and Social Psychology, 69, 1216-1232.

Oyserman, D., \& Markus, H. (1990). Possible selves and delinquency. Journal of Personality and Social Psychology, 59, 112-125.

Oyserman, D., Terry, K., \& Bybee, D. (2002). A possible selves intervention to enhance school involvement. Journal of Adolescence, $25,313-326$.

Reynolds, K. J., Jones, B. M., O'brien, K., \& Subasic, E. (2013). Theories of socio-political change and the dynamics of sub-group versus superordinate interests. European Psychologist, 18, 235-244. https:// doi.org/10.1027/1016-9040/a000159

Salmela-Aro, K., Mutanen, P., Koivisto, P., \& Vuori, J. (2009). Adolescents' future education-related personal goals, concerns, and internal motivation during the "towards working life" group intervention. European Journal of Developmental Psychology, 7, 445-462.

Soudien, C. (2004). Constituting the class: An analysis of the process of 'integration' in South African schools. In L. Chisholm (Ed.), Changing class: Education and social change in post-apartheid South Africa (pp. 89-114). Cape Town, South Africa: HSRC Press.

Statistics South Africa. (2012). Census South Africa, 2011. Pretoria, South Africa: Statistics South Africa.

Tajfel, H., \& Turner, J. C. (1986). The social identity theory of intergroup behaviour. In S. Worchel \& W. G. Austin (Eds.), Psychology of intergroup relations (2nd ed., pp. 7-24). Chicago, IL: Nelson-Hall.

Unzueta, M. M., \& Binning, K. R. (2012). Diversity is in the eye of the beholder: How concern for the ingroup affects perceptions of racial diversity. Personality and Social Psychology Bulletin, 38, 26-38.

How to cite this article: Masinga NC, Dumont KB. The motivational implications of adolescents' school-oriented possible identities in a social change context. J Appl Soc Psychol. 2018;00:1-7. https://doi.org/10.1111/jasp.12512 